\title{
Optimalisasi Program Pemasaran Bagi Pelaku Usaha Agrowisata Stroberi
}

Rully Arlan Tjahyadi, A. Rinny Maharsi, Chandra Kuswoyo, Nonie Magdalena, Allen Kristiawan, Ariesya Aprillia, Cen Lu, Kartika Imasari, Agus Aribowo, Kezia Kurniawati, Felicia Abednego, Ika Gunawan, Anny Nurbasari, Asni Harianti, Maya Malinda, Nur, Henky L. Suwarno, Yolla Margaretha, Vinsensius, Jessica Agrippina Fedora, Agatha Evania Alanarima

Universitas Kristen Maranatha, Bandung.

\begin{abstract}
Abstrak: La Fresa sebagai salah satu perusahaan di Lembang memiliki beberapa unit bisnis, salah satu bisnis yang menjadi perhatian khusus adalah wisata stroberi. Hampir semua agrowisata strawberry menawarkan produk dan layanan serupa kepada setiap konsumen. Agar dapat bersaing dan unggul, agrowisata harus mampu berorientasi pada proses pemenuhan keinginan dan kebutuhan konsumen. Oleh karena itu, Jurusan Manajemen Universitas Kristen Maranatha melakukan kegiatan Penelitian dan Pengabdian kepada Masyarakat untuk mengoptimalkan strategi pemasaran La Fresa. Kegiatan ini terdiri dari tiga tahap: (1) identifikasi Segmen, Penargetan, dan Positining (STP), serta bauran pemasaran yang telah dilakukan oleh La Fresa dengan teknik Diskusi Kelompok Fokus (FGD); (2) identifikasi preferensi konsumen untuk agrowisata stroberi dan mengusulkan program pemasaran khusus ke La Fresa dengan teknik distribusi kuesioner; (3) presentasi dan konseling hasil dari FGD dan Riset Pasar.
\end{abstract}

Keywords: Agrotourism, Marketing Mix, Segmentation Targeting Positioning

Abstract: La Fresa as one of the corporations in Lembang has several business units, one of the businesses that is of particular concern is strawberry tourism. Almost all strawberry agrotourism offers similar products and services to each consumer. In order to be able to compete and excel, agrotourism must be able to be oriented towards the process of fulfilling consumer desires and needs. Therefore, Departement of Management Maranatha Christian University conducts Research and Community Service activities in order to optimize marketing strategy La Fresa. This activity consists of three stages: (1) identification of Segments, Targeting, and Positining (STP), as well as the marketing mix that has been carried out by La Fresa with Focus Group Discussion (FGD) techniques; (2) identification of consumers' preferences for strawberry agrotourism and proposed specific marketing programs to La Fresa with questionnaire distribution techniques; (3) presentation and counseling of results from the FGD and Market Research.

Keywords: Agrotourism, Marketing Mix, Segmentation Targeting Positioning 


\section{PENDAHULUAN}

\section{A. Latar Belakang}

Propinsi Jawa Barat merupakan wilayah sentra produksi hortikultura yang utama di Indonesia. Di Jawa Barat, Kabupaten Bandung adalah salah satu sentra produksi hortikultura karena memiliki konidis iklim, lahan, dan sumberdaya hayati yang sangat mendukung pengembangan jenis komoditas tersebut [1] Hortikultura (holticulture) berasal dari bahas Latin-hortus (tanaman kebun) dan cultural (budidaya)-yang diartikan sebagai budidaya tanaman kebun.

Hortikultura meliputi buah-buahan, sayuran, tanaman obat, dan tanaman hias. Komoditas hortikultura yang sangat potensial untuk dikembangkan adalah buahbuahan [1]. Salah satu komoditas holtikultura yang dapat dikembangkan adalah Stoberi. Tanaman stroberi termasuk tanaman yang memiliki nilai ekonomi tinggi, daya tariknya terletak pada warna buah yang merah mencolok dan rasanya manis segar. Buah stroberi mempunyai peluang pasar yang semakin luas, karena buah subtropis ini tidak hanya dikonsumsi secara langsung tetapi stroberi juga dapat diolah menjadi sirup, selai, dodol, manisan, jus, dan bahan baku pembuat es krim [1]. Budidaya stroberi di Lembang berkembang dengan pesat dan telah berkembang menjadi agrowisata stoberi. Agrowisata didefinisikan sebagai suatu bentuk kegiatan pariwisata yang memanfaatkan usaha agro (agrobisnis) sebagai objek wisata dengan tujuan untuk memperluas pengetahuan, pengalaman, rekreasi dan hubungan usaha di bidang pertanian [2]. Agrowisata merupakan bagian dari objek wisata yang memanfaatkan usaha pertanian [3].

La Fresa sebagai salah satu korporasi yang ada di Lembang memiliki beberapa unit bisnis dan yang menjadi perhatian utamanya adalah pada agrowisata stroberi. Hampir seluruh agrowisata stoberi menawarkan produk dan layanan yang serupa kepada setiap konsumennya. Hal ini tentu akan berdampak terhadap persaingan yang sangat ketat di sektor ini. La Fresa tidak hanya bersaing dengan pengusaha tani agrowisata stroberi saja, tetapi juga harus mampu bersaing juga dengan objek pariwisata lainnya untuk menarik para wisatawan. Agar dapat bersaing dan menjadi unggul, agrowisata harus mampu berorientasi pada proses pemenuhan keinginan dan kebutuhan konsumen dan menjadikan pengunjung sebagai prioritas utama dalam memberikan produk yang bernilai, serta pelayanan dan fasilitas terbaik. Program pemasaran yang optimal dan inovatif perlu dikembangkan. Pemasaran tidak hanya fokus pada kegiatan untuk meningkatkan penjulan melalui promosi. Marketing is how you create, 
communicate, and deliver value to customer. Sehingga formulasi dan impelmentasi strategi pemasaran yang holistik sangat diperlukan untuk menciptakan, mengkomunikasi dan menghantarkan nilai kepada pelanggan sehingga dapat bersaing dan memenangkan persaingan.

Berdasarkan latar belakang tersebut, program pemasaran yang optimal dan inovatif sangat diperlukan oleh La Fresa. Program Studi S1 Manajemen Fakultas Ekonomi Universitas Kristen Maranatha mengadakan kegiatan Penelitian dan Pengabdian Kepada Masyarakat (PKM) dalam rangka optimalisasi program pemasaran agrowisata edukasi stroberi La Fresa. Kegiatan ini terdiri dari 3 (tiga) tahap: (1) identifikasi Segmen, Targeting, dan Positining (STP), serta bauran pemasaran yang telah dilakukan oleh $\mathrm{La}$ Fresa dengan teknik Focus Group Discussion (FGD); (2) identifikasi preferensi konsumen agrowisata stroberi dan usulan program-program pemasaran yang spesifik bagi La Fresa dengan teknik penyebaran kuesioner; (3) pemaparan dan penyuluhan hasil dari FGD dan Riset Pasar. Tujuan kegiatan ini bagi UMKM adalah mampu mengidentifikasi STP dan bauran pemasaran (marketing mix); mampu menjalankan kegiatan pemasaran yang optimal dan inovatif berdasarkan pada preferensi konsumen agrowisata stroberi; mampu bersaing dengan agrowisata dan pariwisata lainnya. Tujuan bagi Dosen dan Mahasiswa adalah wujud pelaksanaan kegiatan Tri Dharma Perguruan Tinggi; mampu memberikan solusi yang dihadapi oleh Usaha Mikro Kecil dan Menengah (UMKM); meningkatkan kemampuan praktis bagi dosen dan mahasiswa; serta meningkatkan kepedulian terhadap pengembangan UMKM.

\section{B. Tujuan Kegiatan Penelitian dan PKM}

Kegiatan ini bertujuan untuk memberikan solusi program pemasaran yang harus dijalankan oleh pihak La Fresa. Kegiatan yang dilakukan untuk dapat memberikan solusi tersebut adalah:

1. Mengidentifikasi segmen pasar dan bauran pemasaran yang dilakukan oleh La Fresa.

2. Mengidentifikasi preferensi konsumen terhadap agrowisata stroberi.

\section{Tinjauan Pustaka}

\section{Agrowisata}

Agrowisata dapat didefinikan sebagai perpaduan antara pariwisata dan pertanian yang mana pengunjung dapat mengunjungi kebun atau peternakan untuk membeli produk, menikmati pertunjukan, mengambil bagian aktivitas, makan, atau melewatkan malam bersama di suatu area perkebunan 
atau taman [4]. Agrowisata (argotourism) adalah bentuk kegiatan pariwisata yang memanfaatkan usaha agro sebagai objek wisata yang bertujuan untuk memperluan pengetahuan (knowledge), pengalaman (experience), rekreasi, dan hubungan usaha di bidang pertanian [2]. Ada beberapa jenis agrowisata yang seringkali menjadi tujuan wisata para pengunjung, yaitu berburu dan memancing; festival dan pameran pertanian; kegiatan tur usaha tani; wisata petik sayuran dan buah-buahan; menunggang kuda; pasar ritel petani atau usaha tani; berlibur di usaha tani; menginap dan menikmati makan pagi di rumah petani; menikmati anggur; menikmati keunikan binatang di peternakan; piknik di wilayah usaha tani; bersepeda dan berjalan di area usaha tani; dan program pendidikan usaha $\operatorname{tani}[2]$.

Ada beberapa potensi pertanian yang dapat dikembangkan sebagai objek wisata:

- Perkebunan. Kawasan perkebunan yang kegiatannya merupakan kesatuan yang utuh mulai dari pembibitan sampai dengan pengolahan hasilnya. Perkebunan sebagai objek wisata terdiri atas perkebunan kelapa sawit, karet, the, kopi, kakao, tebu, dan lainnya.

- Hortikultura. Daya tarik tanaman pangan dan hortikultura sebagai objek agrowisata antara lain kebun bunga- bungaan, buah-buahan, sayur-sayuran, dan kebun tanaman obat-obatan/jamu.

- Peternakan. Potensi peternakan sebagai destinasi wisata antara lain cara tradisional dalam pemeliharaan ternak, aspek keunikan pengelolaan, produksi ternak, atraksi peternakan dan peternakan khusus seperti bekisar dan burung puyuh.

- Perikanan. Kegiatan perikanan dapat dibagi menjadi kegiatan penangkapan dan kegiatan budidaya, dan kegiatan tersebut merupakan potensi yang dapat dikembangkan menjadi objek wisata seperti budidaya ikan air tawar, budidaya air payau, budidaya laut [2].

Perencanaan yang tepat sangat diperlukan dalam mengelola agrowisata. Informasi dan data yang bermanfaat sangat berguna dalam dalam melakukan persiapan dan pengembangan kawasan agrowisata. Prinsip yang harus dipahami dalam perencanaan agrowisata adalah kesesuaian dengan rencana pengembangan wilayah tempat agrowisata itu berada, dibuat secara lengkap, pertimbangan terhadap tata lingkungan dan kondisi sosial masyarakat, selaras dengan sumberdaya alam, sumberdaya manusia, sumber dana, dan teknik-teknik yang ada, serta perlu melakukanan kegiatan evaluasi sesuai dengan perkembangan yang ada [5]. 


\section{Segmentasi, Targeting, dan Positioning}

Pemasaran tidak hanya memfokuskan pada kegiatan promosi untuk dapat meningkatkan penjualan perusahaan. Pemasaran adalah salah satu bidang fungsional organisasi dalam menciptakan, mengkomunikasikan dan menyampaikan nilai (value) bagi pelanggan. Tugas utama pemasaran dalam kaitan dengan menciptakan nilai adalah mengidentifikasi apa yang menjadi kebutuhan dan keinginan dari pasar sasaran. Penting bagi bisnis untuk mengidentifikasi segmen pasar yang menjadi target sasarannya sebelum produk dibuat dan ditawarkan ke pasar.

Segmentasi pasar dipahami sebagai pembagian pasar ke dalam kelompokkelompok pasar yang didefiniskan dengan jelas [6]. Segmentasi didefinsikan sebagai proses pengelompokan pasar yang heterogen menjadi segmen- segmen yang memiliki kesamaan dalam hal kebutuhan, keinginan, perilaku dan atau respon terhadap program pemasaran spesifik [7]. Segmentasi pasar menjadikan kegiatan perusahaan lebih terarah dan sumberdaya perusahaan lebih dapat dimanfaatkan secara efektif dan efisien, dan program-program pemasaran yang dijalankan akan lebih disesuaikan dengan setiap segmen pasar yang menjadi sasaran perusahaan [8].
Terdapat 4 (empat) variable yang menjadi basis bagi perusahaan dalam melakukan segmentasi, yaitu demografis, geografis, psikografis, dan perilaku. Segmentasi demografis yaitu membagi pasar menjadi kelompok berdasarkan pada variabel seperti umur, jenis kelamin, besar keluarga, siklus kehidupan keluarga, pendapatan, pekerjaan, pendidikan, agama, ras dan kebangsaan. Segmentasi Geografis yaitu membagi pasar menjadi beberapa unit secara geografi seperti Negara, regional, Negara bagian, kota atau komplek perumahan. Segmentasi psikografis yaitu membagi pembeli menjadi kelompok berbeda berdasarkan pada karakteristik kelas social, gaya hidup atau kepribadian. Segmentasi perilaku yaitu mengelompokkan pembeli berdasarkan pada pengetahuan, sikap, penggunaan atau reaksi mereka terghadap suatu produk [9].

Tujuan dari melakukan segemntasi adalah untuk menentukan target pasar dan pemosisian merek/produk perusahaan sesuai dengan pasar sasarannya. Targeting adalah proses mengevaluasi dan memilih satu atau beberapa segmen pasar yang dinilai paling menarik untuk dilayani dengan program pemasaran spesifik perusahaan. Positioning adalah cara produk, merek, atau organisasi perusahaan dipersepsikan secara relatif dibandingkan dengan produk, merek atau organisasi 
pesaing oleh pelanggan saat ini maupun calon pelanggan [7].

\section{URAIAN KEGIATAN}

\section{Bauran Pemasaran}

Bauran pemasaran merupakan strategi pemasaran yang penerapannya memerlukan pemahaman mendalam dari perusahaan untuk mengkombinasikan varibel-variabel bauran pemasaran (produk, harga, tempat, dan promosi) untuk memaksimalkan kesuksesan aktivitas pemasaran perusahaan [10]. Produk (product) diartikan sebagai sekumpulan atribut berupa fitur, fungsi, manfaat, dan penggunaan yang digunakan untuk memberikan kepuasan konsumen. Harga (price) merupakan salah satu alat pemasaran yang mampu memengaruhi permintaan dan merupakan kunci penggerak posisi produk yang akan memengaruhi bagaimana produk atau merek akan dipersepsikan oleh konsumen dibandingkan dengan produk pesaing. Tempat (place) menyangkut berbagai kegiatan yang dilakukan perusahaan untuk membuat produk dapat diperoleh dan tersedia bagi pelanggan. Tempat berkaitan dengan saluran distribusi. Promosi (promotion) adalah media untuk mengenalkan, mengajak, mempersuasi, dan memengaruhi konsumen untuk mempertimbangkan, membeli, dan konsumsi produk yang ditawarkan oleh perusahaan atau pemasar [10]. 
Agenda Kegiatan

\begin{tabular}{|c|c|c|c|c|}
\hline No & & Kegiatan & $\begin{array}{c}\text { Waktu } \\
\text { Pelaksanaan }\end{array}$ & $\begin{array}{c}\text { Tempat } \\
\text { Pelaksanaan }\end{array}$ \\
\hline 1 & \multicolumn{2}{|c|}{$\begin{array}{l}\text { Focus Group } \\
\text { Discussion }\end{array}$} & $\begin{array}{c}\text { Desember } \\
2018 \\
\end{array}$ & $\begin{array}{l}\text { La Fresa, } \\
\text { Lembang }\end{array}$ \\
\hline \multirow[t]{5}{*}{2} & \multicolumn{2}{|c|}{ Riset Pasar } & & \\
\hline & $\mathrm{a}$ & $\begin{array}{l}\text { Briefing } \\
\text { Surveyor }\end{array}$ & 1 Maret 2019 & $\begin{array}{l}\text { Univeristas } \\
\text { Kristen } \\
\text { Maranatha }\end{array}$ \\
\hline & $\mathrm{b}$ & $\begin{array}{l}\text { Pengumpulan } \\
\text { Data }\end{array}$ & $\begin{array}{c}4 \text { Maret - } 19 \\
\text { April } 2019\end{array}$ & \\
\hline & C & $\begin{array}{l}\text { Pengolahan } \\
\text { Data }\end{array}$ & $\begin{array}{l}19 \text { April } \\
2019\end{array}$ & \\
\hline & $\mathrm{d}$ & $\begin{array}{l}\text { Diskusi Tim } \\
\text { berdasarkan } \\
\text { hasil FGD dan } \\
\text { Riset Pasar }\end{array}$ & $\begin{array}{l}26 \text { April } \\
2019\end{array}$ & $\begin{array}{l}\text { Univeristas } \\
\text { Kristen } \\
\text { Maranatha }\end{array}$ \\
\hline 3 & \multicolumn{2}{|c|}{$\begin{array}{l}\text { Pemaparan Hasil } \\
\text { FGD dan Riset } \\
\text { Pasar }\end{array}$} & 3 Mei 2019 & $\begin{array}{l}\text { La Fresa, } \\
\text { Lembang }\end{array}$ \\
\hline
\end{tabular}

I.

III. HASIL FOCUS GROUP

\section{DISCUSSION DAN RISET PASAR}

\section{A. Hasil Focus Group Discussion}

Kegiatan Focus Group Discussion bertujuan untuk mengidentifikasi kegiatan pemasaran yang dilaksanakan oleh pihak La Fresa. Dalam kegiatan ini, ada 8 tema utama yang akan ditanyakan kepada La Fresa. Tim melakukan observasi di La Fresa sebelum kegiatan FGD dilakukan. Berikut ini akan dipaparkan pertanyaan dan jawaban dari setiap tema tersebut.

1. Profil Usaha

- Sejak kapan Anda memulai usaha ini? Mengapa Anda memilih usaha ini?

Bisnis La Fresa dimulai dari tahun 2011 dan memfokuskan di agrobisnis stroberi. Kendala dalam menjalankan agrobisnis ini adalah keadaan alam, sumberdaya manusia yang memahami budidaya stroberi, peralatan yang digunakan dan lemahnya bargaining power dengan retail modern. Berdasarkan pada kendala yang dihadapi dalam menjalankan agrobisnsi, pemilik ingin mengembangkan usahanya dan memfoskuskan pada agrowisata stroberi.

2. Analisis Usaha

- Bagaimana La Fresa memosisikan dirinya dalam persaingan selama ini? Apakah sebagai pemimpin/ penantang/ pengikut/ perelung? Siapa yang menjadi kompetitor utama dari usaha agrowisata edukasi stroberi La Fresa?

Untuk produksi buah stroberi $\rightarrow$ La Fresa sebagai pemimpin pasar, karena ada beberapa agrowisata lainnya yang mengambil stroberi di La Fresa untuk memenuhi kebutuhan mereka.

Untuk agrowisata $\rightarrow$ La Fresa sebagai pengikut pasar, karena La Fresa bukan yang pertama, sudah ada beberapa agrowisata stroberi yang yang lebih dulu muncul.

Untuk agrowisata edukasi $\rightarrow$ La Fresa sebagai perelung pasar, karena memiliki segmen yang tidak begitu besar tetapi memiliki daya beli potensial.

- Apakah ada unit khusus yang focus ke program marketing? Bagaimana 
evaluasi kegiatan pemasaran yang telah dilakukan? Apakah ada survei umpan balik dari setiap pengunjung atau pengguna produk?

Tidak ada unit khusus yang memikirkan mengenai program pemasaran. Evaluasi program pemasaran selama 6 bulan terakhir ini yaitu mengadakan pertemuan dengan para pegawai secara rutin. Survei umpan baliknya biasanya berasal dari konsumen, baik konsumen yang memberikan secara langsung ataupun pihak La Fresa yang bertanya. La Fresa lebih unggul diproduksi dibandingkan kompetitor lainnya tapi lemah di agrowisatanya.

- Selain sekolah apa pernah menawarkan paket lain ke pihak corporate atau institusi lainnya? Misal sudah mencoba untuk mengundang beberapa komunitas?

Belum pernah secara khusus menawarkan ke pihak korporat atau institusi dan mengundang beberapa komunitas.

3. Segmenting, Targeting, dan Positioning

- Berdasarkan apa La Fresa mensegmentasikan pelanggan/ konsumennya?

La Fresa menggunakan segmentasi Demografis (ukuran keluarga) yaitu family dengan anak kecil berusia TK sampai SD serta orang luar kota bukan orang Bandung misal Jakarta. Saat ini sedang berupaya menjangkau wisatawan mancanegara dari Malaysia, Singapore, dan Arab.

- Siapakah target pasar utama yang dituju oleh La Fresa? Target yang dimaksud adalah yang dianggap akan memberikan kontribusi paling besar dalam bisnis La Fresa.

Target utama La Fresa adalah keluarga dengan anak kecil berusia TK sampai SD. Tapi kendalanya La Fresa bukan One Stop Vacation (tidak ada oleh-oleh, permainan anak-anak, dan lainnya yang berhubungan dengan anak-anak).

- Apa positioning \& diferensiasi yang ingin dibangun La Fresa? Menurut Anda apakah sudah tepat positioning La Fresa saat ini? Apakah perlu repositioning?

Belum terpikir untuk konsep positioning dan diferensiasi La Fresa.

4. Product

- Adakah produk/ layanan utama/khas dari La Fresa? Adakah diferensiasi produk dari merek La Fresa?

Beberapa agrowisata membeli ke La Fresa untuk memenuhi kebutuhan mereka.

- Jika disebut wisata edukatif, edukasi apa yang akan ditawarkan? 
di kebun agrowisata petik kebun yang lain hanya berfokus pada bisnisnya saja, di La Fresa disiapkan tour guide untuk menjelaskan mengenai all about strawberry (menambah knowledge pengunjung). Misal menjelaskan bahwa untuk wisata petik stroberi yang besar dan manis tidak perlu juah-jauh ke luar negeri. Bisa dijelaskan juga bahwa tidak semua stroberi itu asam, ada juga yang manis (seperti yang La Fresa budidayakan) jadi tidak perlu diolah dengan ditambahkan gula. Dijelaskan juga bahwa stroberi juga termasuk buah yang table serve. La Fresa memiliki 6 tour guide, per tour guide dapat melayani 10 orang.

- Adakah tagline/ slogan/ logo serta gimmick khusus yang sudah dilakukan oleh La Fresa agar orang ingat dan mau datang?

Taglinenya "All About Strawberry" $\rightarrow$ Kalau mau wisata petik stroberi besar dan manis datang ke La Fresa.

5. Price

- Bagaimana dengan sistem atau metode penetapan harga yang dilakukan La Fresa, apa dasarnya dan apa tujuan dari penetapan harga yang sudah dijalankan sekarang bagi perusahaan La Fresa?

Cara penetapan harga dengan cara survei ke kompetitor (going rate). Selain going rate, penetapan harga juga ditentukan dengan cara bertanya ke calon klien serta persepsi pribadi.

- Adakah corporate rate? Misal untuk sekolah?

Belum ada corporate rate. Sudah ada beberapa sekolah yang datang, tetapi masih sedikit.

- Adakah channel lain untuk mendapatkan tiket masuk selain harus ke lokasi La Fresa? Misal dengan hotel/ tour dll?

Belum ada secara khusus, baru bekerjasama dengan travel agent yang melayani wisatawan mancanegara dari Arab.

6. Place

- Sejauh mana pemasaran atau distribusi produk La Fresa dan apakah ada cabang?

Masuk ke beberapa retail modern. Sedangkan produk La Fresa dipasarkan ke tiga kota besar yaitu Jakarta, Bandung, dan Surabaya.

- Bagaimana menata layout dari tempat di wisata agrowisata? Apakah Layout agrowisatanya disukai anakanak kah? Apakah layout sudah diatur agar instagrammable?

Menata layout sendiri tanpa ada bantuan dari pihak lain. Layout belum mengena untuk anak-anak kalau 
memang targetnya family dengan anak berusia TK sampai SD. Layout belum instagrammable.

- Apakah signage menuju lokasi jelas atau tidak? Sudahkah listing lokasi di Google Maps?

Signage menuju lokasi jelas sudah cukup jelas. Sudah listing lokasi juga di Google Maps.

\section{Promotion}

- Apa saja bauran promosi yang telah dijalankan oleh La Fresa dan mana yang paling efektif?

Flyer dan brosur. Tetapi belum rutin dilakukan.

- Adakah kendala dalam kegiatan promosi selama ini?

Tujuan promosi yang dilakukan $\mathrm{La}$ Fresa saat ini hanya baru sekedar informasi saja.

- Bagaimana evaluasi kegiatan promosi yang telah dilakukan?

Belum melakukan evaluasi.

8. Interactive Marketing \& Social Media

- Apakah ada admin fokus mengelola media social La Fresa? Apakah sudah menggunakan influencer? Jika ya, siapa? Program yang sudah dijalankan apa saja? Bagaimana update contentnya?

Tidak ada admin untuk Instagramnya. Belum menggunakan influencer. Belum rutin meng-update konten.
- Siapa admin websitenya? Layout website seperti apa? Bagaimana update contentnya?

Belum ada adminnya.

- Apa yang sudah dilakukan untuk menaikkan traffic visit social media? Untuk menaikkan traffic visit social media dapat menggunakan influencer. Belum menggunakan peran influencer.

\section{B. Hasil Riset Pasar dan Pembahasan}

Kegiatan riset pasar/survei pasar dilakukan untuk mengidentifikasi preferensi konsumen terhadap agrowisata edukasi stroberi. Sampel dalam riset pasar ini adalah Sekolah Dasar (SD) dan Taman Kanak-Kanak (TK) yang ada di Bandung. Jumlah SD dan TK yang direncakan untuk dilakukan survei sebanyak 60 sekolah/TK. Jumlah responden dalam kegiatan riset pasar sebanyak 2 (dua) orang dari setiap SD dan TK. Respoden diminta untuk menjawab dan memberikan tanggapan dari setiap pertanyaan dan pernyataan yang ada dalam kuesioner. Terdapat 4 bagian dalam kuesioner, yaitu identitas responden, tanggapan tentang field trip, tanggapan tentang agrowisata stroberi, dan tanggapan tentang la fresa.

Kegiatan survei dan pengolahan data dilakukan oleh mahasiswa aktif Program Studi S1 Manajemen Fakultas Ekonomi 
Universitas Kristen Maranatha yang sedang mengampu mata kuliah Manajemen Bauran Pemasaran dan juga mahasiswa yang sedang mengampu mata kuliah Riset Pasar. Kegiatan survei pasar dan proses olah data dilakukan pada bulan Februari - April 2019.

Hasil pengumpulan data menunjukkan bahwa jumlah SD dan TK yang dapat diolah sebanyak 51 Sekolah/TK, jumlah responden yang mengisi kuesioner sebanyak 97 responden. Bagian berikutnya akan dipaparkan mengenai tanggapan tentang kegiatan Field Trip, tanggapan tentang Agrowisata Edukasi Stoberi, dan tanggapan tentang La Fresa.

1. Tanggapan Responden terhadap Kegiatan Field Trip

TABEL 2

KEGIATAN FIELD TRIP

\begin{tabular}{|l|c|c|}
\hline \multicolumn{3}{|c|}{ Kegiatan Field Trip di Sekolah } \\
\hline \multicolumn{1}{|c|}{ Tanggapan } & Frekuensi & Persentase \\
\hline Ada & 95 & 97,9 \\
\hline Tidak Ada & 2 & 2,1 \\
\hline Total & $\mathbf{9 7}$ & $\mathbf{1 0 0}$ \\
\hline
\end{tabular}

Sumber: Hasil Pengolahan Data

Dilihat dari Tabel 2 dapat diketahui bahwa responden yang mengatakan ada kegiatan Field Trip sebesar 97,9\% dan yang mengatakan tidak ada kegiatan Field Trip sebesar 2,1\%. Berkaitan dengan tujuan, responden menjawab tujuan diadakannya field trip adalah menambah wawasan siswa dan mengenal lingkungan sekitar luar sekolah; memberi pelajaran dan pengalaman secara langsung di tempat yang sebenarnya; memberikan pengalaman dan pengenalan langsung pada objek; mengetahui wisata alam sambil belajar dari lingkungan, mengenal lingkungan, melatih kreativitas, menambah wawasan di luar sekolah dan siswa bisa merasakan/ mengenal alam secara langsung; mengisi waktu istirahat dari kegiatan rutin di sekolah, menambah wawasan, menikmati langsung alam dan bersyukur. Tujuan lainnya adalah kunjungan dan pariwisata, mengenal kegiatan yang disesuaikan dengan tema kurikulum; kemandirian, rasa ingin tahu, kebersamaan, sinkronisasi teori dengan realitas, memupuk kepekaan siswa terhadap lingkungan dan mengembangkan kreatifitas.

2. Tanggapan Responden terhadap Agrowisata Edukasi Storberi

TABEL 3

Persetujuan Kegiatan FIELD TRIP

\begin{tabular}{|l|c|c|}
\hline \multicolumn{3}{|c|}{ Persetujuan Adanya Kegiatan Field Trip } \\
\hline \multicolumn{1}{|c|}{ Tanggapan } & Frekuensi & Persentase \\
\hline Ada & 93 & 95,9 \\
\hline Forum Orang Tua dan Sekolah & 2 & 2,1 \\
\hline Tidak Menjawab & 2 & 2,1 \\
\hline Total & $\mathbf{9 7}$ & $\mathbf{1 0 0}$ \\
\hline
\end{tabular}

Sumber: Hasil Pengolahan Data

Tabel 3 menunjukkan bahwa responden yang Mengatakan Ya sebesar 95,9\% dan 
yang mengatakan Tidak Menjawab serta

Tidak bisa langsung dijawab karena persetujuan kegiatan field trip harus melalui forum Orang Tua dan Sekolah sebesar $2,1 \%$.

TABEL 4

ATRIBUT PRODUK AGROWISATA STROBERI

\begin{tabular}{|c|c|c|c|c|c|c|c|}
\hline \multirow{3}{*}{ No } & \multirow{3}{*}{$\begin{array}{l}\text { Atribut } \\
\text { Produk }\end{array}$} & \multicolumn{6}{|c|}{ Tanggapan Responden } \\
\hline & & \multicolumn{2}{|c|}{ Ya } & \multicolumn{2}{|c|}{ Tidak } & \multicolumn{2}{|c|}{$\begin{array}{c}\text { Tidak } \\
\text { Menjawab }\end{array}$} \\
\hline & & Jml & $\%$ & Jml & $\%$ & Jml & $\%$ \\
\hline 1 & $\begin{array}{l}\text { Memetik } \\
\text { Stroberi }\end{array}$ & 93 & 95.9 & 1 & 1 & 3 & 3.1 \\
\hline 2 & $\begin{array}{l}\text { Menanam } \\
\text { Stroberi }\end{array}$ & 91 & 93.8 & 4 & 4.1 & 2 & 2.1 \\
\hline 3 & $\begin{array}{l}\text { Cooking } \\
\text { Class }\end{array}$ & 87 & 89.7 & 9 & 9.3 & 1 & 1 \\
\hline 4 & $\begin{array}{l}\text { Menanam } \\
\text { Bunga }\end{array}$ & 90 & 92.8 & 6 & 6.2 & 1 & 1 \\
\hline 5 & $\begin{array}{l}\text { Informasi } \\
\text { tentang } \\
\text { Stroberi }\end{array}$ & 96 & 99.0 & 1 & 1 & 0 & 0 \\
\hline 6 & $\begin{array}{l}\text { Photo } \\
\text { Booth }\end{array}$ & 59 & 60.8 & 38 & 39.2 & 0 & 0 \\
\hline 7 & $\begin{array}{l}\text { Petunjuk } \\
\text { Arah }\end{array}$ & 86 & 88.7 & 10 & 10.3 & 1 & 1 \\
\hline 8 & $\begin{array}{l}\text { Lahan } \\
\text { Parkir } \\
\text { Luas }\end{array}$ & 90 & 92.8 & 6 & 6.2 & 1 & 1 \\
\hline 9 & $\begin{array}{l}\text { Tempat } \\
\text { Ibadah }\end{array}$ & 72 & 74.2 & 25 & 25.8 & 0 & 0 \\
\hline 10 & $\begin{array}{l}\text { Pemandu } \\
\text { Wisata }\end{array}$ & 95 & 97.9 & 2 & 2.1 & 0 & 0 \\
\hline 11 & $\begin{array}{l}\text { Tempat } \\
\text { Kuliner }\end{array}$ & 69 & 71.1 & 28 & 28.9 & 0 & 0 \\
\hline 12 & Souvenir & 76 & 78.4 & 21 & 21.6 & 0 & 0 \\
\hline 13 & Goodybag & 84 & 86.6 & 13 & 13.4 & 0 & 0 \\
\hline 14 & $\begin{array}{l}\text { Pelayanan } \\
\text { yang } \\
\text { Ramah }\end{array}$ & 94 & 96.9 & 3 & 3.1 & 0 & 0 \\
\hline 15 & $\begin{array}{l}\text { Karyawan } \\
\text { Responsif } \\
\end{array}$ & 96 & 99.0 & 1 & 1 & 0 & 0 \\
\hline 16 & $\begin{array}{l}\text { Menggam } \\
\text { bar/ } \\
\text { Mewarna }\end{array}$ & 76 & 78.4 & 21 & 21.6 & 0 & 0 \\
\hline 17 & $\begin{array}{l}\text { Permainan } \\
\text { Tradisiona } \\
\text { l }\end{array}$ & 93 & 95.9 & 4 & 4.1 & 0 & 0 \\
\hline 18 & $\begin{array}{l}\text { Kualitas } \\
\text { Buah } \\
\text { Stroberi }\end{array}$ & 92 & 94.8 & 5 & 5.2 & 0 & 0 \\
\hline 19 & $\begin{array}{l}\text { Kebersiha } \\
\mathrm{n}\end{array}$ & 95 & 97.9 & 2 & 2.1 & 0 & 0 \\
\hline 20 & $\begin{array}{l}\text { Kemudaha } \\
\text { n Akses }\end{array}$ & 94 & 96.9 & 3 & 3.1 & 0 & 0 \\
\hline 21 & $\begin{array}{l}\text { Paket } \\
\text { Wisata }\end{array}$ & 89 & 91.8 & 7 & 7.2 & 1 & 1 \\
\hline
\end{tabular}

Tabel 4 menunjukkan bahwa responden yang mengatakan memetik stroberi 95,9\%, menamam stroberi 93,8\%, cooking class 89,7\%, menanam bunga 92,8\%, informasi tentang stroberi $99 \%$, photo booth $60,8 \%$, petunjuk arah 88,7\%, tempat parkir yang luas $92,8 \%$, tempat ibadah $74,2 \%$, pemandu wisata $97,9 \%$, tempat kuliner $71,1 \%$, souvenir $78,4 \%$, goodybag $86,6 \%$, pelayanan yang ramah 96,9\%, karyawang yang cepat tanggap 99\%, menggambar/mewarna78,4\%, permainan tradisional 95,9\%, kualitas buah stroberi 94,8\%, kebersihan 97,9\%, kemudahan mencapai lokasi 96,9\%, dan paket wisata 91,8\%. Hasil lainnya berdasarkan pertanyaan terbuka perihal tanggapan responden terhadap atribut produk adalah cara menanam, merawat, manfaat stroberi, hasil olahan, dan hasil karya yang bermanfaat/berguna sebesar 9,3\%. Atribut lainnya adalah harga tiket terjangkau 7,2\%, layanan edukasi yang menyenangkan dan game outdoor, hasil karya yang berguna (artinya dapat dipakai dalam kehidupan sehari-hari) sebesar 5,2\%. 
TABEL 5

NAMA TEMPAT EDUKASI STROBERI YANG DIKETAHU

\begin{tabular}{|c|c|c|}
\hline Nama Tempat & Jumlah & Persentase \\
\hline Tidak Tahu/Menjawab & 40 & 41.2 \\
\hline Cihideung & 2 & 2.1 \\
\hline $\begin{array}{l}\text { Little Farmer, Cikole, Jendela } \\
\text { Alam }\end{array}$ & 2 & 2.1 \\
\hline Little Farmer & 1 & 1 \\
\hline $\begin{array}{l}\text { Vin’s Berry, Grafika, Asep } \\
\text { Stroberi }\end{array}$ & 1 & 1 \\
\hline Kebun Stroberi & 1 & 1 \\
\hline All About Strawberry & 4 & 4.1 \\
\hline Ciwidey & 5 & 5.2 \\
\hline Lembang & 8 & 8.2 \\
\hline Vin’s Berry & 5 & 5.2 \\
\hline Rumah Stroberi & 13 & 13.4 \\
\hline Lembang dan Cihanjuang & 1 & 1 \\
\hline High Land dan La Fresa & 1 & 1 \\
\hline Kebun Stroberi dan La Fresa & 1 & 1 \\
\hline Vin’s Berry dan Orchad & 1 & 1 \\
\hline Rumah Stroberi dan La Fresa & 1 & 1 \\
\hline Ciwidey dan Cihideung & 1 & 1 \\
\hline Ciwidey dan Lembang & 1 & 1 \\
\hline $\begin{array}{l}\text { Vin’s Berry dan Jendala } \\
\text { Alam }\end{array}$ & 1 & 1 \\
\hline Jendela Alam & 1 & 1 \\
\hline Kampung Stroberi & 3 & 3.1 \\
\hline Grafika & 1 & 1 \\
\hline Ciwidey, Cikole, Cihideung & 1 & 1 \\
\hline $\begin{array}{l}\text { Rumah Stroberi dan All } \\
\text { About Stroberi }\end{array}$ & 1 & 1 \\
\hline Total & 97 & 100 \\
\hline
\end{tabular}

Tabel 5 menunjukkan bahwa nama tempat Argowisata Stroberi yang diketahui/dikenal responden adalah Rumah
Stroberi sebesar 13,4\%, Lembang sebesar 8,2\%, Ciwidey dan Vin's Berry sebesar

5,2\% dan All about Stroberi sebesar 4,1\%.

3. Tanggapan Responden terhadap La Fressa

TABEL 6

NAMA EDUKASI STROBERI LA FRESA

\begin{tabular}{|l|c|c|}
\hline \multicolumn{3}{|c|}{ Mengetahui La Fresa } \\
\hline \multicolumn{1}{|c|}{ Tanggapan } & Frekuensi & Persentase \\
\hline Ya & 14 & 14,4 \\
\hline Tidak Mengetahui & 83 & 85,6 \\
\hline Total & $\mathbf{9 7}$ & $\mathbf{1 0 0}$ \\
\hline
\end{tabular}

Sumber: Hasil Pengolahan Data

Berdasarkan pada Tabel 6, responden yang tidak mengetahui La Fresa sebagai agrowisata stroberi sebesar $85,6 \%$ atau 83 responden menjawab tidak mengetahui $\mathrm{La}$ Fresa, dan sisanya $14,4 \%$ atau 14 responden mengenal La Fresa.

TABEL 7

TANGGAPAN TERHADAP CITRA LA FRESA

\begin{tabular}{|l|c|c|}
\hline \multicolumn{3}{|c|}{ Citra terhadap La Fresa } \\
\hline \multicolumn{1}{|c|}{ Tanggapan } & Frekuensi & Persentase \\
\hline $\begin{array}{l}\text { Stroberi Matang dan Dapat } \\
\text { Dipetik Sendiri }\end{array}$ & 2 & 2,1 \\
\hline Tidak Menjawab & 89 & 91,8 \\
\hline $\begin{array}{l}\text { Menarik, Mengesankan, } \\
\text { Terjaga Kebersihannya } \\
\text { tempatnya, Aman untuk } \\
\text { Anak-anak, Cocok sebagai } \\
\text { Sarana Belajar, Pelayanan } \\
\text { Baik dan Bagus }\end{array}$ & 6 & 6,2 \\
\hline Total & $\mathbf{9 7}$ & $\mathbf{1 0 0}$ \\
\hline
\end{tabular}

Sumber: Hasil Pengolahan Data

Berdasarkan pada Tabel 7, dapat diketahui bahwa responden yang Tidak Menjawab sebesar 91,8\%, diurutan kedua yang mengatakan Tempat wisata yang menarik, sebagai media belajar untuk anak dengan menikmati langsung memetik 
stroberi yang dapat diolah menjadi minuman/makanan sebesar 6,2\% dan diurutan ketiga yang mengatakan banyak strawberry yang sudah matang dan bisa dipetik sendiri sebesar 2,1\%.

TABEL 8

KUNJUNGAN KE LA FRESSA

\begin{tabular}{|l|c|c|}
\hline \multicolumn{3}{|c|}{ Menggunjungi La Fresa } \\
\hline \multicolumn{1}{|c|}{ Tanggapan } & Frekuensi & Persentase \\
\hline Belum Pernah & 11 & 11,3 \\
\hline Tidak Menjawab & 83 & 85,6 \\
\hline Ya & 3 & 3,1 \\
\hline Total & $\mathbf{9 7}$ & $\mathbf{1 0 0}$ \\
\hline
\end{tabular}

Sumber: Hasil Pengolahan Data

Berdasarkan pada Tabel 8, dapat diketahui bahwa responden yang Tidak Menjawab sebesar 85,6\%, yang mengatakan Belum pernah sebesar 11,3\% dan yang mengatakan Ya Pernah sebesar $3,1 \%$.

TABEL 9

FREE TRIAL

\begin{tabular}{|l|c|c|}
\hline \multicolumn{3}{|c|}{ Free Trial La Fresa } \\
\hline \multicolumn{1}{|c|}{ Tanggapan } & Frekuensi & Persentase \\
\hline Ya & 68 & 70,1 \\
\hline Tidak & 29 & 29,9 \\
\hline Total & $\mathbf{9 7}$ & $\mathbf{1 0 0}$ \\
\hline
\end{tabular}

Sumber: Hasil Pengolahan Data

Dilihat dari Tabel 9 Free Trial La Fresa La Fresa diatas dapat diketahui bahwa responden yang Mengatakan Ya sebesar 70,1\%, dan yang mengatakan Tidak sebesar $29,9 \%$.

\section{REKOMENDASI}

\section{Rekomendasi dari Hasil Focus Group} Discussion

Berdasarkan hasil Focus Group Discussion dengan pihak La Fressa, kami memberikan beberapa simpulan dan memberikan rekomendasi bagi La Fresa:

1. Sebaiknya ikut perkumpulan pengusaha misal di Bandung untuk membangun jejaring.

2. Mengadakan gathering dengan perkumpulan travel agent dan driver sehingga mereka dapat memromosikan La Fresa.

3. Kerjasama dengan orang desain interior dan arsitek untuk mengembangkan layout dan desain La Fresa.

4. Memaparkan keunggulan dan keunikan dari La Fresa di setiap media promosinya termasuk di videography. Misal stroberi yang besar dan manis, dengan tingkat kemanisan 10-11 brix di musim hujan dan 14-15 brix di musim kemarau (stroberi yang biasa tidak akan mencapai double digit brix).

5. Strawberry Family sudah ada tetapi belum dibuat patung, boneka, tempat foto, dll. Sebaiknya Strawberry Family tersebut dijadikan media promosi agar dapat terjadi WOM (Word of Mouth).

6. Brosur dan pamflet yang lebih informative dan menarik. 
2. Rekomendasi Hasil Focus Group Discussion

Berdasarkan hasil riset yang telah dilakukan, 80\% responden belum mengenal nama La Fresa, bahkan untuk menyebutkan kategori produk agrowisata edukasi stroberi, 1 responden dari 90 responden yang menjawab La Fresa atau hanya 1\% responden yang mengisi La Fressa ketika responden diminta menyebutkan Agrowisata Stroberi. Penting bagi La Fressa untuk membangun Brand Awareness.

Merek (brand) menjadi konsep yang sangat penting bagi produk perusahaan, termasuk bagi agrowisata stroberi $\mathrm{La}$ Fressa. Merek dapat dijadikan sebagai alat untuk membedakan produk perusahaan dengan produk pesaing, merek menjadi tanda kualitas/nilai suatu produk. Sehingga penting bagi perusahaan untuk membangun merek yang kuat (Strong Brand).

Salah satu dimensi penting dalam membangun merek yang kuat adalah Brand Awareness. Brand awareness penting dalam memengaruhi sikap dan perilaku konsumen terhadap produk. Sikap dan Perilaku konsumen tersebut ditunjukkan dengan intensi konsumen untuk membeli, purchase behavior, dan loyalitas.

Ada 2 konsep penting yang perlu diperhatikan dalam membangun brand awareness, yaitu brand recognition dan brand recall. Brand recognition dipahami sebagai kemampuan konsumen untuk mengenali suatu produk (konsumen mengenal produk melalui visual dari produk tersebut seperti logo, slogan, symbol, warna). Brand Recall dipahami sebagai kemampuan konsumen untuk mengingat nama sebuah merek dari memori mereka berdasarkan kategori produk (konsumen cukup mendengar kategori produk untuk mengingat merek produk tersebut). Upaya-upaya yang perlu dilakukan La Fressa dalam membangun Brand Recognition dan Brand Recall adalah:

- Membangun intearksi dengan konsumen melalui Social Media.

Hal ini bisa dilakukan dengan beberapa cara, antara lain:

- Membuat konten yang menarik dimana para konsumen dari La Fresa bisa ikut terlibat di dalam nya.

- Membuat platform pada media sosialnya termasuk website nya yang lebih menarik.

- Mendorong followers untuk membagikan konten La Fresa (retweet, regram, dll.). La Fresa harus meluangkan waktu untuk berinteraksi dengan followers, agar followers merasa ada kedekatan emosional sehingga mereka dengan suka cita utk retweet/ regram/ dan sejenisnya. 
- Menyediakan tenaga admin yang bertugas untuk mengurus semua media social La Fresa.

- Membuat kuis/ kontes/ sejenisnya di media sosial La Fresa dan setelah itu memberikan reward.

- Bagikan produk La Fresa secara gratis pada event-event tertentu dgn syarat like/share/retweet/ dan sejenisnya pada media sosial yang dimiliki oleh La Fresa.

- Membuat narasi pemasaran yang menarik yang menunjukkan bahwa La Fressa memang expert dalam hal Stroberi.

- Membuat Video Marketing (Youtube dan Video Facebook).

- Melakukan kerjasama dengan influencer/buzzer untuk memperkuat citra merek La Fresa.।

- Melakukan Event Marketing dan atau Live event.

- Membuat souvenir-souvenir (merchandise) yang behubungan dengan La Fressa.

- Membuat logo melalui penciptaan karakter Mr dan Mrs. Strawberry yang dimiliki oleh La Fresa. Hal ini dapat menarik perhatian anak-anak sebagai target utama dalam kegiatan field trip dan menciptakan brand recognition.
- Membuat spanduk/ reklame/ tanda usaha La Fresa di tempat - tempat yang menjadi segmen utama lebih baik lagi.

- Sponsorship.

- Melakukan co-branding dengan brand yg lebih terkenal yg memiliki profil calon konsumen yg sama.

- Menyebarkan flyer pada pihak-pihak sekolah dan khususnya kepada orang tua siswa.

- Membuat profiling brand.

\section{UCAPAN TERIMA KASIH}

Kegiatan Penelitian dan Pengabidan Kepada Masyarakat ini dilaksanakan atas kerjasama antara Fakultas Ekonomi Universitas Kristen Maranatha dan La Fresa. Kami menyampaikan terima kasih atas dukungan semua pihak, khususnya Fakultas Ekonomi Universitas Kristen Maranatha dan La Fresa yang telah mendanai kegiatan ini. Kami sangat mengaharapkan bahwa kegiatan ini dapat memberikan manfaat baik baik Fakultas Ekonomi maupun bagi pihak La Fresa.

LAMPIRAN FOTO KEGIATAN 


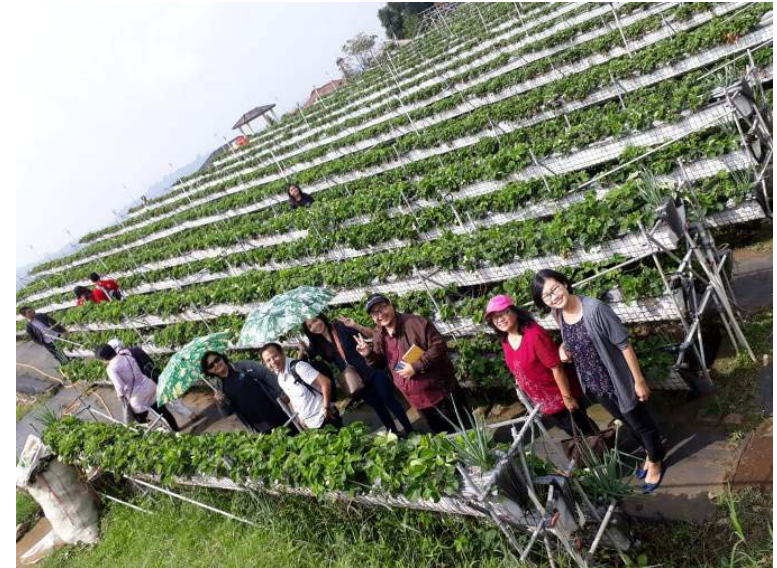

Gambar 1. Obervasi Agrobisnis La Fresa

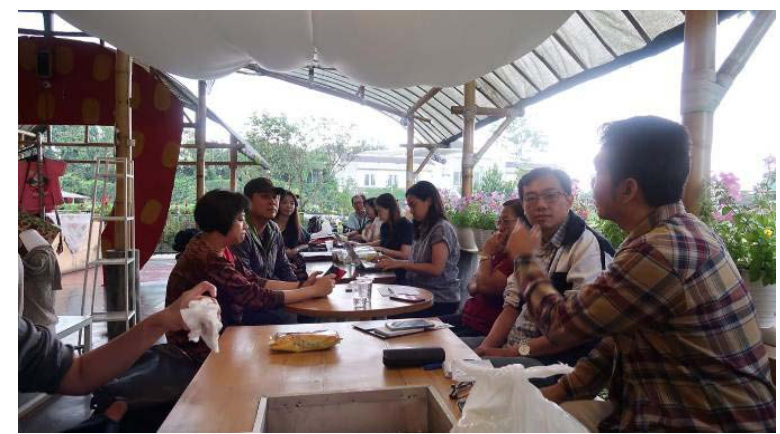

Gambar 2. Kegiatan Focus Group Discussion dengan Pihak La Fresa

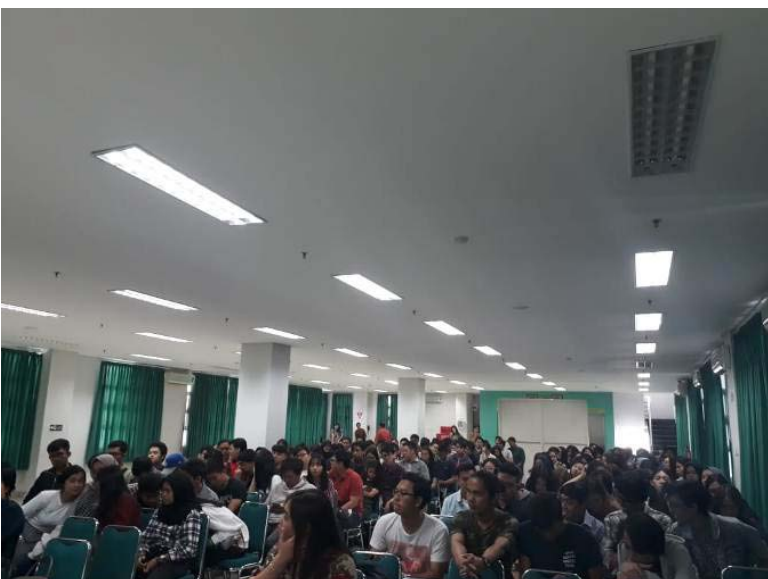

Gambar 3. Kegiatan Focus Group Discussion dengan Para Mahasiswa sebagai Surveyor Riset

Pasar

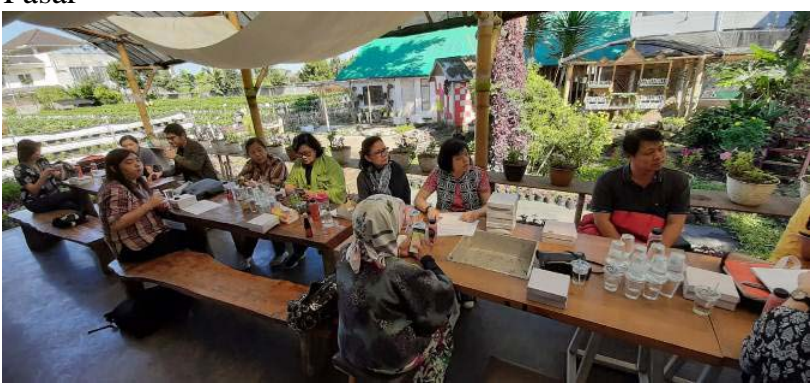

Gambar 4. Kegiatan Pemaparan Hasil Riset Pasar dan Rekomendasi.

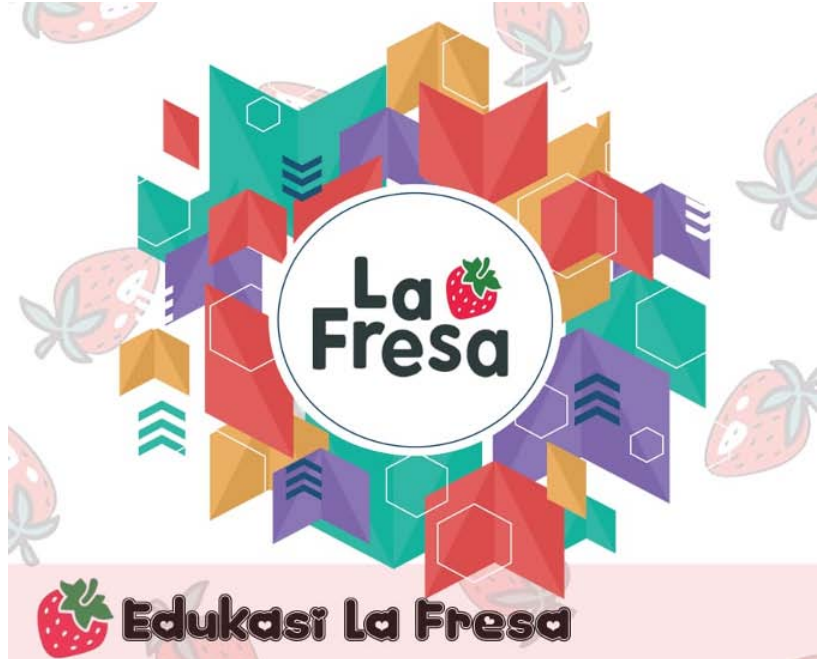

Agrowisata La Fresa adalah sebuah tempat wisata untuk media belajar anak-anak bermain dengan alam dengan memetik buah strawberry langsung dari kebun dan menanam tanaman bunga

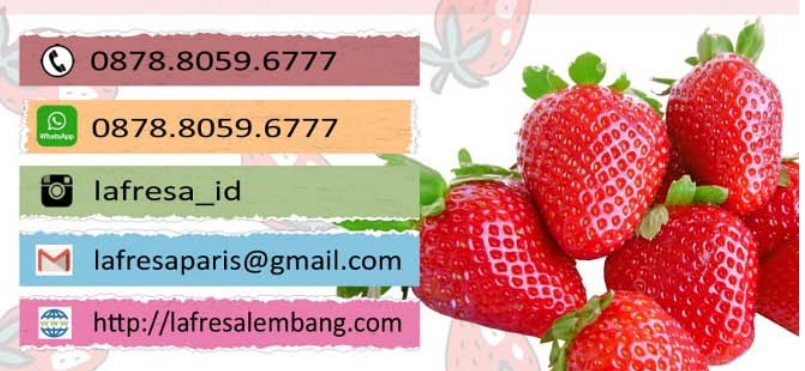

Gambar 5. Desain Brosur untuk La Fresa. 


\section{DAFTAR PUSTAKA}

[1] A. N. Ashari, "Repository IPB Website," July 2016.[Online].Available: https://repository.ipb.ac.id/bitstream/ handle/ 123456789/86062/H16ana.pdf? sequence $=1 \&$ isAllowed $=\mathrm{y}$. [Accessed 21 January 2019].

[2] R. U. I. G. Bagus, "Researchgate," April 2011.

[Online]. Available:

https://www.researchgate.net/ publication/277074027_AGROWISATA_S EBAGAI_PARIWISATA_ALTERNATIF. [Accessed January 2019].

[3] B. Pamulardi, "Pengembangan Agrowisata Berwawasan Lingkungan," Universitas Diponegoro, Semarang, 2006.

[4] Ismayanti, Pengantar pariwisata, Jakarta: PT Grasindo, 2010.

[5] M. R. Tirtawinata, Daya Tarik dan Pengelolaan Agrowisata, Penebar Swadaya, 1996.

[6] P. K. a. K. L. Keller, Marketing Management, Upper Saddle River, New Jersey: Prentice Hall, 2012.

[7] F. T. d. G. Chandra, Pemasaran Strategik, Yogyakarta: C.V. Andi, 2012.

[8] R. Savitra, "Analisis Pengaruh Strategi Segmenting, Targeting dan Positioning Terhadap Keputusan Pelanggan Membeli Nu Green Tea," Jurnal Ekonomi dan Manajemen, vol. 6, no. 1, pp. 28-43, 2017.

[9] R. H. Hanafrian, "Tinjauan Strategi Segmentasi, Targeting, Positioning (STP) pada PT Soka Cipta Niaga," e-Proceeding of Applied Science, vol. 3, no. 2, pp. 338344, 2017.

[10] H. U. d. I. Firdaus, "Pengaruh Bauran Pemasaran terhadap Perilaku Online Shopping: Perspektif Pemasaran Agribisnis," Jurnal Ecodemica, vol. 2, no. 1, pp. 136-146, 2018. 